\title{
An Inquiry into the Causes of Inflation in Sri Lanka: An Eclectic Approach
}

\author{
Danusha Jayawardana and Prabhath Jayasinghe
}

\begin{abstract}
The objective of this study is to identify the short and long-run determinants of inflation in Sri Lanka. It follows an eclectic approach to seeking possible determinants of inflation and employs an Autoregressive Distributed Lag (ARDL) bounds testing approach to test for co integration between inflation and its causes. The findings indicate that increased money supply, depreciation of the rupee and higher public wages are the major causes of inflation in both the short and long-run. Thus, it can be stated that inflation in Sri Lanka is affected by both demand and supply side factors, which highlights the importance of a prudent and effective implementation of the monetary and fiscal policies so as to ensure a stable macroeconomic environment in Sri Lanka.
\end{abstract}

Keywords: ARDL model, determinants, error correction model, inflation, Sri Lanka

\section{Introduction}

Inflation, which is commonly defined as a persistent increase in the general price level over a long period of time, is considered to be one of the most researched topics in economics. It is a key macroeconomic variable that has serious implications on growth and income distribution. High levels of inflation can have a series of adverse impacts on the standard of living of the people. It affects the consumption and savings patterns of households as well as investment decisions of business firms. It also affects the proper functioning of economic activities, leading to low levels of economic growth and development. High inflation can also bring about negative social and political consequences.

Danusha Jayawardana, is a Lecturer of School of Accounting and Business of the Institute of Chartered Accountants of Sri Lanka. E-mail: danushaj@yahoo.com

Prabhath Jayasinghe, $\boldsymbol{P h D}$ is a Professor in the Department of Business Economics, Faculty of Management \& Finance, and University of Colombo. E-mail: prabhath@dbe.cmb.ac.lk (Corresponding author) 
Controlling inflation or achieving price stability has been regarded as an important objective of Sri Lanka's overall economic policy since independence. When reviewing the past experience of inflation during the post-independence period of Sri Lanka, it is evident that the rate of inflation has been subjected to fluctuations due to changes in both domestic and international factors. Particularly, during the post-liberalisation era, the rate of inflation, as measured by the Colombo Consumers' Price Index (CCPI), has remained high and volatile and has thus emerged as a major problem within the economy (Karunaratne \& Bandara 2000).

Controlling the rate of inflation is essential for a stable macroeconomic environment. Volatile inflation makes it difficult for individuals as well as business firms to correctly predict the future rate of inflation leading to short-term speculative activities. In addition, accurate predictions of inflation are also vital for efficient policy making and implementation.

Controlling inflation requires that its causes be correctly identified. However, according to the vast number of theories of inflation as well as empirical studies, inflation is caused by numerous determinants, thus making it difficult to ascertain which variable or determinant to control so as to maintain a desirable level of inflation.

As discussed below, the few studies carried out on inflation in Sri Lanka rely heavily on a single approach to inflation and thus only on a few explanatory variables. This study aims to inquire into the external and internal causes of inflation in Sri Lanka during the postliberalization period through an eclectic approach that uses a combination of explanatory variables suggested by a number of different approaches such as demand-pull, cost-push and structuralist. It is believed that the findings of this study will contribute to a better understanding of existing inflation and provide useful insights into the effective control of inflation in Sri Lanka.

The rest of the study is organized as follows. Section two presents the theoretical framework and Section three a brief literature review on inflation in Sri Lanka. Section four outlines the proposed econometric model and the method used. Measures of the variables and the sources of data are described in Section five. Empirical findings are reported and then discussed in Section six. Finally, concluding remarks are included in Section seven.

\section{Theoretical Framework}

According to the relevant theoretical explanations and empirical studies, inflation is caused by variety of factors. On the demand-pull front, the money supply growth is a major determinant 


\section{NSBM Journal of Management}

Vol. 2, No. 1, January - June, 2016

of inflation. As per the Quantity Theory of Money, there is a one-for-one relationship between the growth of money supply and the rate of inflation. The increase in government expenditure may also lead to inflation in two ways: it has a direct impact on inflation through an increase in aggregate demand and may also lead to a budget deficit, which the government may have to close by borrowing from inflationary sources. As the Philips curve relationship reveals, an increase in real GDP can trigger inflation.

On the cost-push front, wage increases are inflationary whenever the increase in the nominal wage rate exceeds productivity growth. Such increases in wages lead to higher production costs thereby resulting in a decrease in aggregate supply, which would result in high prices. Wages can also be inflationary from a demand-push point of view as increased wages will enhance aggregate demand. A sharp increase in the price of basic resources such as crude oil and the occurrence of natural disasters that reduces aggregate supply in an economy - usually known as 'supply shocks' in the literature - can also be inflationary.

The Fisher hypothesis suggests that there is a one-for-one relationship between nominal interest rate and expected inflation, a causal arrow running from inflation to interest rates. However, the relationship can also be viewed from a cost-push perspective where the causation is in the reverse direction. If the interest rate is taken as a cost of borrowing, an increase in the interest rate may increase costs of production, thus leading to higher prices.

Inflation may occur together with the depreciation of the domestic currency as it results in an increase in the price of imports (which includes both consumption and capital goods). Inflation and currency depreciation may even reinforce each other creating a vicious cycle in some developing economies.

The structuralists/post Keynesians stress that, though the factors such as budget deficits and currency depreciation are seeming determinants of inflation, they are just propagatory factors. The root causes of inflation are the factors which give birth to these propagatory factors. For instance, the reason behind budget deficits in most of the less developed countries is the inelasticities associated with raising government revenue and inevitable government expenses on various socio-political factors (Nicholas 1993). Along the same lines, the depreciation of domestic currency in such economies occurs mostly due to trade and production constraints. The increase in the price of basic necessities, especially essential food items, is also another example. Particularly in the context of developing countries, such price increases are a result of various supply rigidities in the agricultural sector and resultant supply shortages. Sunkel (1960 as cited in Basu 2003) argues that the distributional conflicts between workers and 
capitalists over income shares can lead to an increase in nominal wages as well as profits resulting in inflationary pressure.

Finally, expectations of inflation are a vital source of any ongoing inflation because people predict the future on the basis of current and past inflation, thus creating a self-fulfilling process. This study uses an eclectic approach by accommodating most of the above factors as determinants of inflation in Sri Lanka.

\section{Review of Literature on Inflation in Sri Lanka}

Quite a number of studies have been conducted with respect to the determinants of inflation in Sri Lanka. Examining the main determinants of inflation in Sri Lanka for the period of 1980 to 2005, Ratnasiri (2009) reports that Sri Lanka's inflation is influenced by both demand and supply side factors in the short-run as well as in the long-run. According to Ratnasiri (2009), money supply growth and the increase in the price of rice are the most important determinants. However, in the short run, exchange rate depreciation can also influence inflation whereas GDP growth does not exert any influence on inflation either in the shortrun or in the long run. Based on these findings, Weerasekara (1992) posits that money supply growth and depreciation of the exchange rate are the main determinants of inflation in Sri Lanka. However, according to Nicholas (1993), inflation in Sri Lanka, particularly during the period of 1971 to 1987, had been caused by factors such as currency depreciation, budget deficits, world market prices and food prices while there is no strong relationship between money supply and inflation. Cooray (2008), in a study that estimates a price equation for Sri Lanka under both closed and open economy scenarios, suggests greater support for the open economy model and concludes that supply side factors are important in influencing the general price level in Sri Lanka. According to Duma (2008), external shocks explain only about 25 percent of the variation in consumer price inflation in Sri Lanka. In his study, only a combination of external variables, namely, exchange rate, oil prices and import price shocks, is used to identify the external impact on inflation. In an attempt to identify the impact of petroleum prices on inflation in Sri Lanka, Perera (2005) finds that there is an indirect impact of changes in diesel prices on inflation which is much larger than the direct impact.

Overall, according to most of the empirical studies on inflation in Sri Lanka, it is evident that both demand and supply side factors are among the important sources of inflation. However, based on the above literature on inflation pertaining to Sri Lanka it can be stated that there is no comprehensive study which explores the impact of all the important variables that are likely to cause inflation. 
NSBM Journal of Management

Vol. 2, No. 1, January - June, 2016

\section{The Proposed Model and the Econometric Method}

Given that chosen macroeconomic variables are more likely to have non-linear relationships, all the variables have been converted into linear form by taking their natural log values. Based on the discussion in Section 2, the model given by equation (1) is proposed to analyze the determinants of inflation in Sri Lanka.

$$
\begin{aligned}
\ln P_{t}=\propto_{0}+\propto_{1} \ln M_{t}+\propto_{2} \ln E_{t}+\propto_{3} \ln O P_{t} & +\propto_{4} \ln B D_{t}+\propto_{5} \ln Y_{t} \\
& +\propto_{6} \ln W_{t}^{S}+\propto_{7} \ln W_{t}^{P}+\propto_{8} D_{01}+\propto_{9} D_{04}+U_{t}
\end{aligned}
$$

where $P_{t}$ is price level represented by the Colombo Consumers' Price Index; $M_{t}$ is nominal broad money supply (i.e. $\mathrm{M}_{2}$ ); $E_{t}$ is nominal exchange rate between the Sri Lankan rupee and the US dollar; $O P_{t}$ is average price of a barrel of crude oil in US dollar terms; $B D_{t}$ is annual budget deficit of government fiscal operations; $Y_{t}$ is real gross domestic product; $W_{t}^{S}$ is nominal public wage index; $W_{t}^{P}$ is nominal private wage index; $D_{01}$ is a dummy to capture the impact of the power crisis in 2001; $D_{04}$ is a dummy to capture the impact of the tsunami disaster in 2004.

The Autoregressive Distributed Lag (ARDL) Bounds Testing approach has been selected to find the co integration relationships between the variables in question. The main advantage of the ARDL approach is that, while other co integration techniques require all of the regressors to be integrated of the same order, ARDL can be applied irrespective of their order of integration. It thus avoids the pre-testing problems associated with standard cointegration tests (Pesaran, Shin \& Smith 2001). Moreover, with ARDL, it is possible that different variables have differing optimal numbers of lags. In addition, ARDL is better suited for small samples.

The key argument of this approach is that the independent variables may influence the dependent variable with a lag as well as the dependent variable may be correlated with its own lags, thus requiring the inclusion of the lags of the independent variables as well as of the dependent variable in the regression.

The ARDL model used to check the co integration between the price level and other variables is given in equation (2). 


$$
\begin{gathered}
\Delta \text { In } P_{t}=\beta_{0}+\theta_{0} \text { In } P_{t-1}+\theta_{1} \text { In } M_{t-1}+\theta_{2} \text { In } E_{t-1}+\theta_{3} \text { In } O P_{t-1}+\theta_{4} \text { In } W_{t-1}^{S} \\
+\theta_{5} \text { In } Y_{t-1}+\theta_{6} \operatorname{In} W_{t-1}^{P}+\sum_{i=1}^{p} \beta_{1_{i}} \Delta \operatorname{In} P_{t-1}+\sum_{i=0}^{q} \beta_{2_{i}} \Delta \operatorname{In} M_{t-i} \\
+\sum_{i=0}^{q} \beta_{3_{i}} \Delta \operatorname{In} E_{t-i}+\sum_{i=0}^{q} \beta_{4_{i}} \Delta \operatorname{In} O P_{t-i}+\sum_{i=0}^{q} \beta_{5_{i}} \Delta \operatorname{In} W_{t-i}^{S} \\
+\sum_{i=0}^{q} \beta_{6_{i}} \Delta \operatorname{In} Y_{t-i}+\sum_{i=0}^{q} \beta_{7_{i}} \Delta \operatorname{In} W_{t-i}^{P}+\mu_{t}
\end{gathered}
$$

In terms of the unrestricted ECM given by equation (2), the joint null hypothesis to be tested, which implies the absence of a long-term relationship between price level and the explanatory variables, is $\theta_{0}=\theta_{1}=\theta_{2}=\theta_{3}=\theta_{4}=\theta_{5}=\theta_{6}=0$. Testing the joint statistical significance of all thetas is performed with the help of a $F$ test. However, in ARDL modeling, the standard critical values of the F statistic are not effective. Since the order of integration can be either $I(0)$ or $I(\mathrm{I})$, Pesaran et al. (2001) suggest two sets of alternative critical values at each level of significance. One set that represents the lower bound assumes that all regressors are $I(0)$ and the other set that represents the upper bound assumes that they are $I(1)$. If the computed F statistic is less than the lower bound for critical values (i.e. $F<F_{L}$ ), the null hypothesis of $\theta_{0}$ $=\theta_{1}=\theta_{2}=\theta_{3}=\theta_{4}=\theta_{5}=\theta_{6}=0$ cannot be rejected. On the other hand, if the computed $\mathrm{F}$ value is greater than the upper bound for critical values (i.e. $F>F_{U}$ ), then the null hypothesis is rejected and this supports the view that there exists a long-term relationship between the price level and the explanatory variables. However, if the computed $F$ value lies between the lower and upper bound critical values (i.e. $F_{L}<F<F_{U}$ ), the inference is said to be inconclusive and the order of integration of the variables in question has to be investigated further.

\section{Data and Measures}

In Sri Lanka, changes in price levels are captured by three price indices, namely, the Colombo Consumers' Price Index (CCPI), Wholesale Price Index (WPI) and the Gross Domestic Product (GDP) deflator. However, when it comes to measuring inflation, the CCPI (Base $1952=100$ ) which is computed by the Department of Census and Statistics (DCS) has been used as the official price index since 1953.CCPI was revised in 2007 as well as in 2011 when the base years were changed to 2002 and 2006/07 respectively. However, in this study the dependent variable of inflation will be measured by CCPI with 1952 as the base year and the required data for the period of 2008 - 2014 were obtained through the splicing method $^{1}$ in order to ensure the consistency of the data series.

1 Splicing is a statistical method of combining two or more index numbers covering different bases into a single series. 


\section{NSBM Journal of Management}

Vol. 2, No. 1, January - June, 2016

As for the money supply, different studies have used different monetary aggregates in order to assess their impact on inflation. According to the quantity theory of money, there is a direct influence from the nominal stock of money on the changes of price levels. Therefore, the nominal money supply is chosen over the real money supply which is assumed to be represented by the nominal broad money supply $\left(M_{2}\right)$. Both Ratnasiri (2009) and Weerasekara (1992) indicate that broad money supply is better at predicting inflation than the narrow definitions of money supply.

The annual overall deficit of government fiscal operations is taken to represent the budget deficit. This represents the difference between total government revenue including grants and total government expenditure for a given year. The absolute values of the deficit figures are considered for estimation purposes.

The GDP at constant prices with the base year of 1982 is used to represent the real national income. Though it is possible to find a number of series of real GDP calculated using different base years, the base year selected in this study is 1982. Real GDP figures with 1982 as the base year were available only for the period from 1982 to 1996 . Therefore, the corresponding GDP figures for 1977 - 1981 and 1996 - 2014 are obtained through the splicing method.

Rather than taking one wage index, wages are assumed to be represented by two wage indices: public sector and private sector nominal wage indices. This division makes sense as public wage increases are not usually matched by productivity increases whereas it may not be so in the case in wages in the private sector, suggesting that increases in public sector wages are more likely to be inflationary. The nominal wage rate index (NWRI), base year of which is 1978 , of all central government employees is selected to represent the public wages while the private wages are proxied by the nominal wage rate index of workers in wage board trades. This will make it possible to identify the importance of the type of wage in explaining inflation.

In order to capture the pass through of exchange rate movements to inflation, it is necessary to determine the exchange rate that matters the most in inflation in Sri Lanka. Even though the nominal effective exchange rate (NEER) would have been a better representation, the nominal bilateral exchange rate between the Sri Lankan rupee and the US dollar is used instead due to the non-availability of a long-term series of NEER. However, this selection is also consistent with the previous studies of Cooray (2008), Duma (2008), Ratnasiri (2009) and Weerasekara (1992). 
According to Duma (2008), oil prices can also be considered an important source of inflation in Sri Lankan context. Thus, in this study, oil prices are represented by the average price of a barrel of crude oil in US dollar terms.

In addition to the above determinants, dummy variables have also been used to capture the unusual behavior of inflation through supply shocks. Two dummy variables are employed to capture the effect of the power crisis during the year 2001 and the impact of the tsunami in 2004. In 2001 Sri Lanka faced an energy crisis resulting in power outages and rationing from July to November 2001. Daily power cuts started with a one-and-a-half hour blackout in the evening and increased to eight hours a day. It is argued that this energy crisis influenced most of the macroeconomic variables including the general price level. This was also reflected in a negative growth of GDP in 2001. In order to identify whether this had a significant effect on inflation, a dummy variable has been employed. Furthermore, it is a known fact that the tsunami disaster which occurred in December 2004 brought in many social and economic consequences. Thus, to capture its effect on inflation, a dummy variable, the value of which is equal to 1 for the observation in 2005 and zero otherwise, has been employed. The study has been limited to only these two dummy variables in order to ensure the principle of parsimony.

This study uses annual data for the period from 1977 to 2014 and all the required data are obtained from the annual reports, monthly bulletins and economic and social statistics published by the Central Bank and from the publications of the Department of Census and Statistics. The reason for selecting an annual data series instead of quarterly and monthly frequencies is the non-availability of monthly and quarterly data for certain variables such as budget deficit and real GDP.

\section{Empirical Analysis and Discussion of Findings}

All the series were obtained in natural log form. The ADF test under Schwartz information criteria was conducted to test the stationarity of the series. The unit root test results of the series given in Table 1 suggest that all series are not integrated of the same order. Money supply, exchange rate and budget deficit are $I(0)$ while all the other series are $I(1)$. 
NSBM Journal of Management

Vol. 2, No. 1, January - June, 2016

Table 1: Unit Root Test Results of the Series (1977 - 2014)

\begin{tabular}{|c|c|c|c|c|c|c|}
\hline \multicolumn{3}{|c|}{ Level form } & \multicolumn{3}{|c|}{ First difference form } & \multirow[t]{3}{*}{ Results } \\
\hline \multirow{2}{*}{$\begin{array}{l}\text { Variable } \\
\text { on level }\end{array}$} & \multicolumn{2}{|c|}{ ADF stats } & \multirow{2}{*}{$\begin{array}{c}\text { Variable } \\
\text { on first } \\
\text { difference }\end{array}$} & \multicolumn{2}{|c|}{ ADF stats } & \\
\hline & $\begin{array}{c}\text { Without } \\
\text { trend }\end{array}$ & $\begin{array}{l}\text { With } \\
\text { trend }\end{array}$ & & $\begin{array}{c}\text { Without } \\
\text { trend }\end{array}$ & $\begin{array}{l}\text { With } \\
\text { trend }\end{array}$ & \\
\hline $\ln \mathrm{P}_{\mathrm{t}}$ & -2.62 & -1.65 & $\Delta \ln P_{t}$ & $-4.27 * * *$ & $-4.88 * * *$ & $\mathrm{I}(1)$ \\
\hline $\ln \mathrm{M}_{\mathrm{t}}$ & -1.02 & $-3.40 *$ & $\Delta \ln M_{t}$ & $-2.75^{*}$ & $-2.83^{*}$ & $\mathrm{I}(0)$ \\
\hline $\ln \mathrm{E}_{\mathrm{t}}$ & $-3.48 * *$ & $-4.47 * * *$ & $\Delta \ln E_{t}$ & $-12.60 * * *$ & $-13.80 * * *$ & $\mathrm{I}(0)$ \\
\hline $\ln \mathrm{OP}_{\mathrm{t}}$ & -0.82 & -1.55 & $\Delta \ln O P_{t}$ & $-5.97 * * *$ & $-5.90 * * *$ & $\mathrm{I}(1)$ \\
\hline $\ln \mathrm{BD}_{\mathrm{t}}$ & -0.72 & $-7.64 * * *$ & $\Delta \ln B D_{t}$ & $-5.14 * * *$ & $-5.03 * * *$ & $\mathrm{I}(0)$ \\
\hline $\ln Y_{t}$ & 1.39 & -0.07 & $\Delta \ln Y_{t}$ & $-4.38 * * *$ & $-4.71 * * *$ & $\mathrm{I}(1)$ \\
\hline $\ln \mathrm{W}_{\mathrm{t}}^{\mathrm{S}}$ & -1.09 & -1.93 & $\Delta \ln W_{t}^{S}$ & $-4.89 * * *$ & $-4.91 * * *$ & $\mathrm{I}(1)$ \\
\hline $\ln \mathrm{W}_{t}^{\mathrm{P}}$ & -2.27 & -1.94 & $\Delta \ln W_{t}^{P}$ & $-5.86 * * *$ & $-3.63 * * *$ & $\mathrm{I}(1)$ \\
\hline
\end{tabular}

Note: $* * *, * *$ and $*$ denote the statistical significance at $1 \%, 5 \%$ and $10 \%$ levels respectively

Given that the variables within the selected sample period are a mix of $I(0)$ and $I(1)$ processes, the ARDL bounds testing approach has been employed to test for the long-term relationships among the variables. Accordingly, the unrestricted version of the model represented by Equation 2 against the restricted version given by the assumption that all thetas and level terms are absent in the same equation has been used to obtain the relevant $F$ statistic for the annual data. The optimal lag lengths for the variables are selected on the basis of minimum Akaike's Information Criterion (AIC). The selected model contains contemporaneous terms and an intercept ${ }^{2}$. The computed $F$-statistic is then compared with the asymptotic critical value bounds provided by Pesaran et al. (2001).

According to the critical values tabulated in Table 02, it is evident that the computed $F$ statistic of the annual series 4.51 is greater than the upper bound for critical values 4.26 even at a 99 percent confidence level. These results suggest that the price level and the relevant variables are co integrated.

2 The AIC criterion was checked only up to one lag as the inclusion of two or more lags would affect the principle of parsimony. 
Table 2: ARDL Bounds Testing Approach Results

\begin{tabular}{|c|c|c|c|c|}
\hline \multirow{3}{*}{$\begin{array}{l}\text { Computed } \\
F \text {-statistic }\end{array}$} & \multicolumn{4}{|c|}{ Asymptotic critical value bounds for $F$-statistic } \\
\hline & \multicolumn{2}{|c|}{$95 \%$} & \multicolumn{2}{|c|}{$99 \%$} \\
\hline & $I(0)$ & $I(1)$ & $I(0)$ & $I(1)$ \\
\hline 4.51 & 2.32 & 3.50 & 2.96 & 4.26 \\
\hline
\end{tabular}

An Error Correction Model (ECM) was estimated to identify the long-run and short-run impact of each variable on inflation under the selected data frequency. The long-run determinants of the model and their respective elasticities are reported in Table 3.

Table 3: Long Run Determinants

\begin{tabular}{cc}
\hline Variable & Coefficient \\
\hline $\ln M_{t}$ & $0.38^{* * * *}$ \\
$\ln E_{t}$ & $0.26^{* *}$ \\
$\ln O P_{t}$ & -0.04 \\
$\ln B D_{t}$ & -0.04 \\
$\ln Y_{t}$ & 0.02 \\
$\ln W_{t}^{S}$ & $0.27 * * *$ \\
$\ln W_{t}^{P}$ & 0.02 \\
\hline
\end{tabular}

Notes: $* * *, * *$ and $*$ denote the statistical significance at $1 \%, 5 \%$ and $10 \%$ levels respectively. The results are based on the following regression model $\ln P_{t}=\propto_{0}+\propto_{1} \ln M_{t}+\propto_{2} \ln E_{t}+\propto_{3} \ln O P_{t}+\propto_{4} \ln B D_{t}+\propto_{5}$ $\ln Y_{t}+\propto_{6} \ln W_{t}^{S+} \propto_{7} \ln W_{t}^{P}+$ error $_{\mathrm{t}}^{3}$

It is evident that the money supply which is represented by the broad money supply is an important long-run determinant of inflation. In line with the monetarist view of inflation, the coefficient of the money supply is positive though it does not represent a one-for-one relationship between money supply and inflation. Increases in exchange rate (depreciation of local currency) lead to increases in inflation in the long run. Given the nature of relatively inelastic demand for imports in Sri Lanka, the depreciation of local currency can be thought to apply pressure on domestic prices. Increases in public sector wages are also inflationary in the sense that such increases are highly unlikely to be matched by productivity increases

3 In order to improve the validity of both models, the intercept and the dummy variables were excluded as they were found to be insignificant. 
in the public sector. In summary, the findings of this study imply that the increase in broad money supply, depreciation of the rupee and increases in public wages are the causes of inflation in Sri Lanka in the long-run. These findings corroborate the findings of Cooray (2008) and Ratnasiri (2009).

Table 4: Short Run Determinants of Inflation

\begin{tabular}{cc}
\hline Variable & Coefficient \\
\hline$\Delta \ln M_{t}$ & $0.34^{* *}$ \\
$\Delta \ln E_{t}$ & $0.16^{*}$ \\
$\Delta \ln O P_{t}$ & -0.0004 \\
$\Delta \ln B D_{t}$ & -0.03 \\
$\Delta \ln Y_{t}$ & -0.04 \\
$\Delta \ln \mathrm{W}_{\mathrm{t}}^{\mathrm{S}}$ & $0.18^{*}$ \\
$\Delta \ln \mathrm{W}_{\mathrm{t}}^{\mathrm{P}}$ & 0.16 \\
Error Correction Term & $-0.47^{* * * *}$ \\
\hline
\end{tabular}

Notes: $* * * * *$ and $*$ denote the statistical significance at $1 \%, 5 \%$ and $10 \%$ levels respectively. The results are based on the following ECM: $\Delta \ln P_{t}=\theta_{1}+\theta_{2}$ error $_{\mathrm{t}-1}+\propto_{1} \Delta \ln M_{t}+\propto_{2} \ln E_{t}+\propto_{3} \Delta \ln O P_{t}+\propto_{4} \Delta \ln B D_{t}+\propto_{5}$ $\Delta \ln Y_{t}+\propto_{6} \ln \Delta W_{t}^{S_{+}} \propto_{7} \ln \Delta W_{t}^{P}+\mathrm{u}_{\mathrm{t}}$

Short-run determinants and their respective elasticities are tabulated in Table 4. The results are consistent and increase in money supply, depreciation of the rupee and increase in public wages are the causes of inflation in the short-run too. Then error correction term is negative and significant. More specifically, $47 \%$ of any deviation from the long-run equilibrium following a short-run disturbance that occurred during the last time period is corrected in the current time period. In the view of Bannerjee, Dolado and Mestre (1998) [as cited in Pahlavani and Rahimi 2009], a highly significant error correction term is further proof of the existence of a stable long-term relationship.

The findings of this study also indicate that oil prices, budget deficits, economic growth and private sector wage increases are not significant determinants of inflation either in the short-run or long-run. Contrary to popular belief, supply shocks also do not play a key role in determining inflation in Sri Lanka in both the short- and long-run. Coefficients of both dummies in Equation (1) are insignificant. As Figure 1 also makes it clear, it is apparent that the power crisis in 2001 and the tsunami disaster in 2004 have not had a significant impact on inflation. 
Figure 1: Inflation During Period of 2001:1 - 2006:12

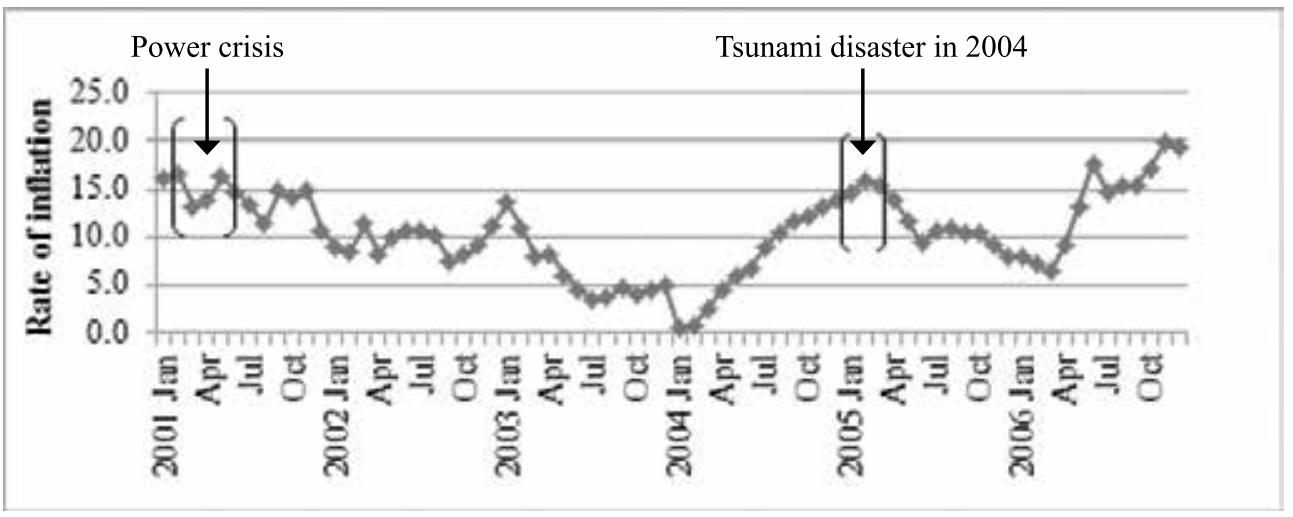

Source: Central Bank of Sri Lanka Annual Report: Various Issues

Figure 2: The Plots of CUSUMQ of the Long- and Short-Run Models

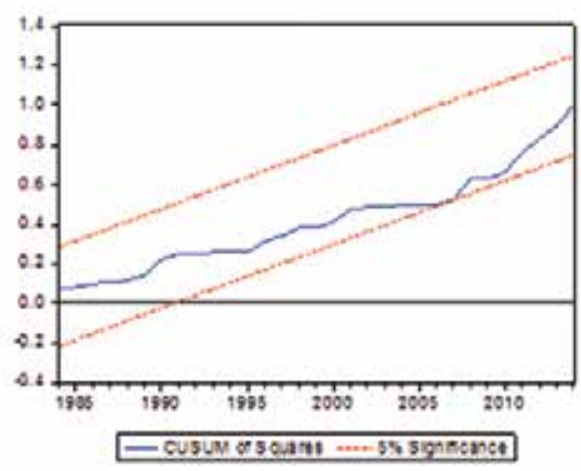

CUSUMQ test of the long-run model

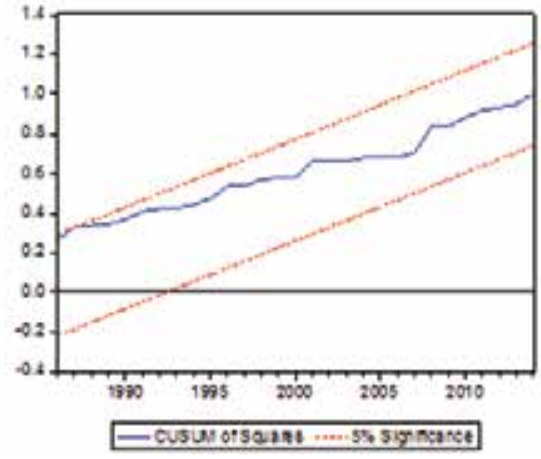

CUSUMQ test of the short-run model

In order to check the stability of the estimated long- and short-run models, a cumulative sum of squared residuals (CUSUMQ) test was performed and the resultant diagrams are shown in Figure 2. It is evident that the plots of CUSUMQ of both the long- and short-run models are within the five percent significance level boundaries. This gives credence to the fact that the regression coefficients of the estimated models remained stable over the selected time period.

\section{Conclusion}

This study inquired into the short-run and long-run determinants of inflation in Sri Lanka, using annual data for the period from 1977 to 2014. It contributes to the existing literature on 


\section{NSBM Journal of Management}

Vol. 2, No. 1, January - June, 2016

inflation by using an eclectic approach in selecting the possible determinants of inflation in Sri Lanka. Considering the existing theoretical and empirical developments, an econometric model was specified containing a wide range of determinants of inflation, including money supply, exchange rate, prices of crude oil, budget deficit, real gross domestic product, public wage index, private wage index and dummy variables representing supply shocks.

In view of the autoregressive distributed lag (ARDL) approach to co integration, it was found that there exists a significant long-run relationship among the variables under study. The empirical findings of ECM indicates that the increase in broad money supply, depreciation of the rupee and increase in public wages influence the rate of inflation in both the long- and short-run. Thus, it can be stated that inflation in Sri Lanka is affected by both the demand and supply side factors ${ }^{4}$. Furthermore, the results of ECM of the selected frequency indicate that the coefficient of the error correction term is significant with the expected sign. It suggests a high speed of convergence towards equilibrium if there is a disequilibrium shock in the previous period.

The findings of this study highlight the importance of the effective implementation of monetary policy as money supply has a significant effect on inflation. In addition, proper management of exchange rate is also vital as depreciation of the exchange rate can cause inflation in both the long-and short-run. Besides, it is evident that increases in public wages are inflationary; therefore, proper supply side policies must be implemented to minimize its adverse impact on inflation. In conclusion, it is vital for policy makers to control the above determinants of inflation so as to achieve price stability and thereby to ensure a stable macroeconomic environment in Sri Lanka.

\section{References}

Basu, K 2003, Analytical development economics: The less developed economy revisited, viewed 16 November 2013, http://books.google.com/

Central Bank of Sri Lanka Annual Report, various issues, Central Bank of Sri Lanka, Colombo.

Cooray, AV 2008, 'A model of inflation for Sri Lanka', Review of Applied Economics, vol. 4, no. 1-2, pp. 35-44.

Duma, N 2002, 'Pass-through of external shocks to inflation in Sri Lanka', IMF Working Paper, no. 08/78, International Monetary Fund, Washington, USA.

4 One of the limitations of this study is the non-availability of sufficiently lengthy time series data for certain important variables. 
Karunaratne, ND \& Bandara, Y 2000, 'Inflation in post-independence Sri Lanka', in Sri Lanka's Development Since Independence: Socio-Economic Perspectives and Analyses, pp. 209-224, Lakshman, WD and Tisdell, CA (eds), Nova Science Publishers, New York, USA.

Nicholas, HVB 1993, Inflation in Sri Lanka 1971-87: A preliminary study, Macroeconomic Series, Institute of Policy Studies, Colombo, Sri Lanka.

Pahlavani, M \& Rahimi, M 2009, 'Sources of inflation in Iran: An application of the ARDL approach', International Journal of Applied Economics and Quantitative Studies, vol. 6, no. 1, pp. 61-76.

Perera, WTK 2005, 'The impact of petroleum prices on inflation in Sri Lanka', Staff Studies, vol. 35, no. 1 \& 2, pp. 107-127, Central Bank of Sri Lanka.

Pesaran, HM, Shin, Y \& Smith, RJ 2001, 'Bounds testing approaches to the analysis of long run relationships', Journal of Applied Economics, vol. 16, pp. 289-326.

Ratnasiri, HPGS 2009, 'The main determinants of inflation in Sri Lanka - A VAR based analysis', Staff studies, vol. 39, no. 1 and 2, pp.1-14, Central Bank of Sri Lanka.

Weerasekara, YMWB 1992, 'Inflation in Sri Lanka - A Causality Analysis', South East Asian Central Banks Centre staff paper, no 46. South East Asian Central Banks Research and Training Centre, Kuala Lumpur. 